\title{
Periádica Eletrânica

\section{MONITORAMENTO DE QUALIDADE DE ÁGUA: SUPORTE PARA GESTÃO AMBIENTAL NA MICROBACIA DO CÓRREGO DA OLARIA}

\author{
Antonio Lucio Mello Martins ${ }^{1}$
}

Maria Conceição Lopes²

Mariana Bárbara Lopes Simedo ${ }^{3}$

\begin{abstract}
RESUMO
O monitoramento é um dos instrumentos de gestão estabelecidos na Política Nacional de Recursos Hídricos, com vistas ao enquadramento dos corpos d'água em classes, segundo seus múltiplos usos. Os objetivos deste trabalho foram avaliar os aspectos qualitativos dos corpos hídricos quanto à classificação do Índice da Qualidade da Água - IQA e seu enquadramento de acordo com a Resolução CONAMA 357/2005, relacionado com o uso do solo da Microbacia Hidrográfica do Córrego da Olaria. O experimento foi conduzido no período de 01 de outubro de 2013 a 30 de setembro de 2014 no Polo Regional Centro Norte - APTA, Pindorama, SP. Esta microbacia possui uma área de $9,17 \mathrm{~km}^{2}$ e faz parte da sub-bacia hidrográfica do rio São Domingos, pertencente à Bacia Hidrográfica dos rios Turvo e Grande. Os parâmetros químicos bacteriológicos: dureza total, amônio, nitrato, nitrogênio, fósforo e coliformes fecais foram analisados mensalmente. As coletas das amostras de água ocorreram em seis nascentes e foz, em áreas de pastagens e matas da Unidade. Os parâmetros indicaram que os valores obtidos diferiram em cada ponto. Comprovou-se que o manejo do solo nas vertentes influenciou na qualidade do recurso hídrico. A qualidade das águas da Microbacia Córrego da Olaria alcança a classe 2 segundo CONAMA 357/2005, água doce própria para comunidades aquáticas e uso agrícola.
\end{abstract}

PALAVRAS-CHAVE: Qualidade da Água. Bacia Hidrográfica. Manejo do Solo.

\section{WATER QUALITY MONITORING: SUPPORT FOR ENVIRONMENTAL MANAGEMENT IN THE WATERSHED OF THE STREAM POTTERY}

\author{
ABSTRACT \\ Monitoring is one of the management tools established the National Water Resources Policy, with a \\ view to the classification of water bodies into classes according to their multiple uses. The objectives \\ of this study were to evaluate the qualitative aspects of water bodies on the classification of the Water \\ Quality Index - AQI and its framework in accordance with Resolution CONAMA 357/2005, related to \\ the land use of the micro basin of Pottery stream. The experiment was carried out from 1 October

\footnotetext{
${ }^{1}$ Engenheiro Agrônomo, Dr., Pesquisador Científico VI na APTA - Polo Regional Centro Norte. Imartins@apta.sp.gov.br

${ }^{2}$ Bióloga, mestre em Agronomia, Ciência do Solo. Oficial de ApCT, APTA - Polo Regional Centro Norte.conceicao@apta.sp.gov.br

${ }^{3}$ Tecnóloga em Agronegócio, Mestranda em Agronomia, Programa Ciência do Solo na FCAVUNESP. mariana_blopes@hotmail.com
} 


\section{Periódica Eletrânica \\ Fórum Ambiental}

da Alta Paulista

2013 to 30 September 2014 for Polo Regional Centro Norte - APTA, Pindorama, SP. This watershed has an area of $9,17 \mathrm{~km}^{2}$ and is part of the watershed of the river São Domingos, belonging to the hydrographic basin of the rivers Grande and Turvo. Bacteriological chemical parameters: total hardness, ammonium, nitrate, nitrogen, phosphorus and fecal coliforms were analyzed monthly. The collection of water samples occurred in six springs and mouth, in pastures and woods of Unity. The parameters indicate that the obtained values differ at each point. It was shown that soil management in the areas affected the quality of water resources. The quality of the Watershed Stream Pottery water reaches class 2 seconds CONAMA 357/2005, own fresh water for agricultural use and aquatic communities..

KEYWORDS: Water Quality. Watershed. Soil Management.

\section{MONITOREO DE LA CALIDAD DEL AGUA: APOYO A LA GESTIÓN AMBIENTAL EN LA CUENCA DE LA CERÁMICA STREAM}

\section{RESUMEN}

El monitoreo es una de las herramientas de gestión establecidos la Política Nacional de Recursos Hídricos, con miras a la clasificación de las masas de agua en clases de acuerdo a sus múltiples usos. Los objetivos de este estudio fueron evaluar los aspectos cualitativos de los cuerpos de agua en la clasificación del Índice de Calidad del Agua - AQI y su marco de conformidad con la Resolución CONAMA 357/2005, relacionado con el uso de la tierra de la micro cuenca del arroyo de la cerámica. El experimento se llevó a cabo desde octubre 1, 2013 a septiembre 30, 2014 para Polo Regional de Centro Norte - APTA, Pindorama, SP. Esta cuenca tiene una superficie de 9,17 km2 y es parte de la cuenca del río Santo Domingo, perteneciente a la cuenca hidrográfica de los ríos Grande y Turvo. Parámetros químicos bacteriológicos: dureza total, amonio, nitrato, nitrógeno, fósforo y coliformes fecales fueron analizadas mensualmente. La recolección de las muestras de agua se produjo en seis muelles y de la boca, en los pastos y bosques de la Unidad. Los parámetros indican que los valores obtenidos difieren en cada punto. Se demostró que la gestión del suelo en las áreas afectada la calidad de los recursos hídricos. La calidad del agua de la cerámica de la Cuenca Arroyo llega clase 2 segundos CONAMA 357/2005, propia de agua dulce para uso agrícola y las comunidades acuáticas.

PALABRAS CLAVE: Calidad del Agua. Cuenca Hidrográfica. Manejo de Suelo.

\section{INTRODUÇÃO}

O monitoramento é um dos instrumentos de gestão estabelecidos na Política Nacional de Recursos Hídricos, com vistas ao enquadramento dos corpos d'água em classes, segundo os usos preponderantes da água. Para este enquadramento, são estabelecidos padrões de qualidade (BRASIL, 2005). Segundo Magalhães Jr. (2000), o monitoramento deve ser visto como um processo essencial à implementação dos instrumentos de gestão das águas, pois permite a obtenção de informações estratégicas, acompanhamento das medidas efetivadas, atualização dos bancos de dados e o direcionamento das decisões.

De acordo com Belitz et al. (2004), monitorar a qualidade das águas brasileiras oferece a base necessária ao gerenciamento do referido recurso, auxiliando na tomada de decisão e analisando a eficácia das decisões tomadas, com foco na manutenção, remedição, proteção e manutenção dos recursos hídricos. 
De acordo com Reis (2009), a cada dia se torna mais evidente a relação entre as alterações nas bacias hidrográficas ocasionadas pelo desenvolvimento de atividades antrópicas em seu entorno. A existência destas alterações leva a necessidade de se criar uma gestão integrada dos recursos hídricos.

A bacia hidrográfica é definida como uma área de captação natural da água da precipitação que faz convergir os escoamentos para um único ponto de saída, seu exutório. É composta basicamente de um conjunto de superfícies vertentes e de uma rede de drenagem formada por cursos d'água que confluem até resultar um leito único no exutório (SILVEIRA, 2001).

Nas subdivisões da bacia hidrográfica aparece na literatura o termo microbacia. Uma variedade de conceitos é aplicada na definição de microbacias, podendo ser adotados critérios como unidades de medida, hidrológicos e ecológicos (LEONARDO, 2003).

A caracterização da qualidade da água é um elemento essencial para a gestão dos recursos hídricos (ANA, 2005). A qualidade da água pode ser avaliada por meio de parâmetros físicos e químicos como $\mathrm{pH}$, oxigênio dissolvido, temperatura, condutividade elétrica entre outros.

De acordo com Donadio et al. (2005), o uso de indicadores físico-químicos da qualidade da água consiste no emprego de variáveis que se correlacionam com as alterações ocorridas na microbacia, sejam essas de origem antrópica ou natural. Segundo Lopes (2011), a qualidade do recurso hídrico está intensamente ligada ao uso do solo praticado nas vertentes das bacias. A quantificação da qualidade hídrica serve de base para o projeto de planejamento do uso do solo e da aplicação de práticas conservacionistas. A análise da qualidade do recurso hídrico pode detectar ou não a influência dos diferentes usos do solo.

Os corpos de água têm capacidade de assimilar poluentes e autodepurar-se, mas essa capacidade é limitada. O Conselho Nacional do Meio Ambiente (CONAMA), através da Resolução 357/2005, estabelece uma classificação para os corpos de água e oferece diretrizes ambientais para o seu enquadramento, bem como descreve as condições e padrões de lançamento de efluentes, além de outras providencias relacionadas ao assunto (BRASIL, 2005).

Nesse contexto, os objetivos deste trabalho foram avaliar os parâmetros físicos químicos e biológicos de qualidade de água dos corpos hídricos da 
Microbacia Hidrográfica do Córrego da Olaria, quanto à classificação do Índice da Qualidade da Água - IQA e seu respectivo enquadramento de acordo com a Resolução CONAMA 357/2005.

\section{METODOLOGIA}

\subsection{Caracterização da área de estudo}

\subsubsection{Localização geográfica}

O local para realização do presente trabalho é a Microbacia Hidrográfica do Córrego da Olaria, localizada no município de Pindorama - SP; região noroeste do Estado de São Paulo. Apresenta as coordenadas geográficas: entre as latitudes $21^{\circ} 05^{\prime} 47,80^{\prime \prime} \mathrm{S}$ e $21^{\circ} 19^{\prime} 35,93^{\prime \prime} \mathrm{S}$; e longitudes $49^{\circ} 03^{\prime} 02,88^{\prime \prime} \mathrm{W}$ e $48^{\circ} 42^{\prime} 52,27^{\prime \prime} \mathrm{W}$, com uma área de 9,17 $\mathrm{Km}^{2}$, entre as coordenadas UTM, zona 22K, e faz parte da subbacia hidrográfica do rio São Domingos, pertencente a Bacia Hidrográfica dos rios Turvo e Grande (Figura 1). A microbacia situa-se no Polo Regional Centro Norte APTA, Unidade de Pesquisa vinculada à Secretaria de Agricultura do Governo do Estado São Paulo (SAA), com uma área de 532,8 ha e aproximadamente 120 ha de mata nativa, a qual foi transformada em Reserva Biológica em 1986.

Figura 1: Microbacia do Córrego da Olaria. (Fonte: Google Earth)

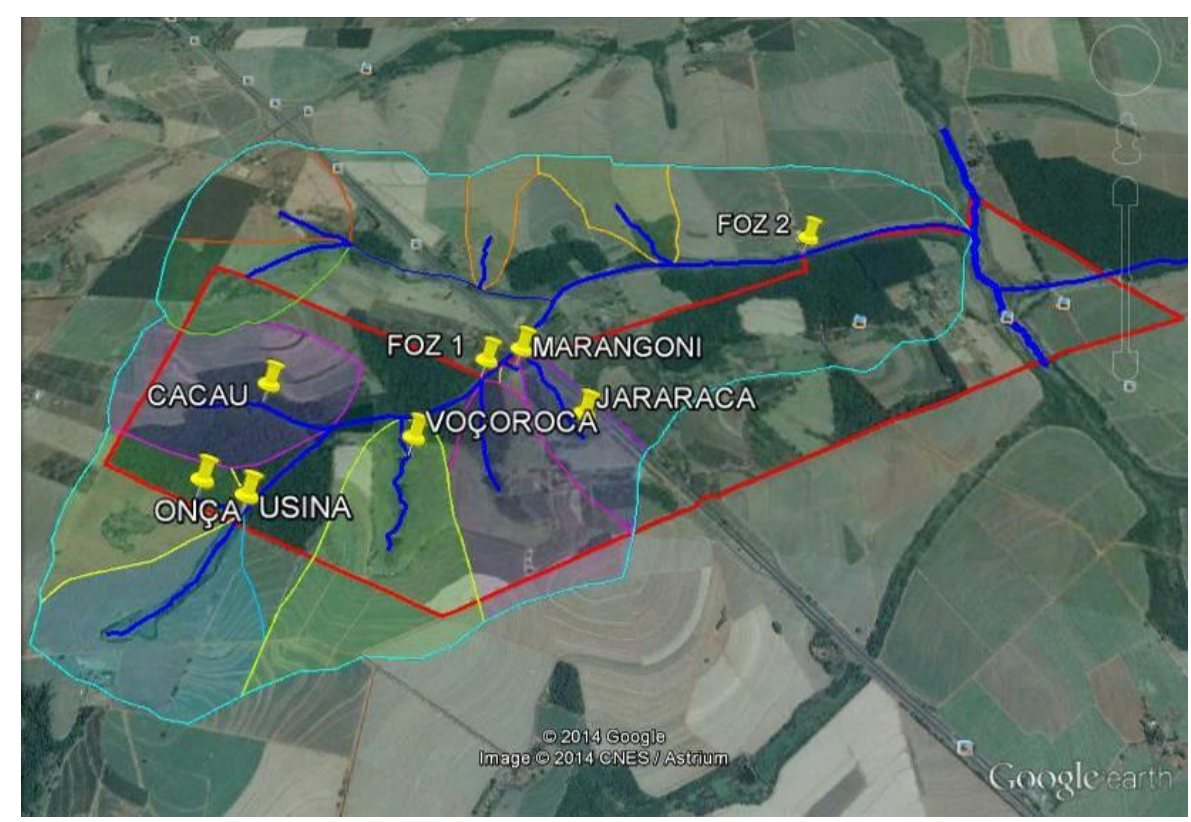

Fonte: GOOGLE EARTH, 2014. 


\section{Periódica Eletrânica

\subsubsection{Clima}

Segundo a classificação climática de Köppen, o clima enquadra-se em Aw, definido como clima mesotérmico de inverno seco, onde a temperatura média do mês mais frio é abaixo de $18^{\circ} \mathrm{C}$ e do mês mais quente, acima de $22^{\circ} \mathrm{C}$.

\subsubsection{Aspectos geológicos e pedológicos}

Geologicamente, a Microbacia do Córrego da Olaria encontra-se na Bacia do Paraná, unidade geotectônica estabelecida sobre a Plataforma Sul Americana a partir do Devoniano Inferior. Estratigraficamente, a área pertence ao Grupo Bauru e Grupo São Bento. O relevo é ondulado nas partes de altitudes maiores, passando a suave-ondulado nas altitudes menores. A maior parte dos declives está compreendida entre $2 \%$ e $10 \%$, havendo pequenas áreas quase planas de $0 \%$ a $2 \%$ de declive, nos topos das elevações e nas várzeas, e algumas com declives entre $10 \%$ e $20 \%$ próximas aos cursos d'água.

\subsubsection{Monitoramento da qualidade do recurso hídrico nas nascentes e foz da microbacia do Córrego da Olaria}

A tabela 1 abaixo relaciona as características das nascentes com as nomenclaturas que foram adotadas em cada uma delas.

Tabela 1: Características dos pontos de coleta de água nas microbacias do Córrego da Olaria

\begin{tabular}{|c|c|c|}
\hline Nascentes & Pontos & Uso e Ocupação do Solo \\
\hline $\begin{array}{l}\text { Nascente } \\
1\end{array}$ & $\mathrm{P} 1$ & Nascente em área de pastagem (reflorestamento em APP) - Marangoni \\
\hline $\begin{array}{l}\text { Nascente } \\
2 \\
\end{array}$ & P2 & $\begin{array}{l}\text { Nascente em área de mata parcialmente em regeneração e reflorestada - } \\
\text { Jararaca }\end{array}$ \\
\hline $\begin{array}{l}\text { Nascente } \\
3\end{array}$ & P3 & Córrego da Olaria, com intensa ocorrência de plantas aquáticas - Foz 1 \\
\hline $\begin{array}{l}\text { Nascente } \\
4\end{array}$ & P4 & $\begin{array}{c}\text { Nascente localizada em mata nativa com marcante presença de serapilheira } \\
\text { Cacau }\end{array}$ \\
\hline $\begin{array}{l}\text { Nascente } \\
\quad 5\end{array}$ & P5 & $\begin{array}{c}\text { Nascente em área de antiga voçoroca recuperada por prática de } \\
\text { conservação de solo (açudes artificiais), com implantação de mata ciliar e } \\
\text { uso de Sistema Agroflorestal (SAF), e apresenta áreas agricultáveis no } \\
\text { entorno - Voçoroca }\end{array}$ \\
\hline $\begin{array}{l}\text { Nascente } \\
6\end{array}$ & P6 & Nascente em área de mata nativa - Onça \\
\hline $\begin{array}{l}\text { Nascente } \\
7\end{array}$ & P7 & Nascente em área agrícola (cultivo de cana-de-açúcar) - Usina \\
\hline $\begin{array}{l}\text { Nascente } \\
8\end{array}$ & P8 & Córrego da Olaria, com intensa ocorrência de vegetação na margem - Foz 2 \\
\hline
\end{tabular}

Fonte: RELATÓRIO FAPESP, 2013 
Para avaliar a qualidade do recurso hídrico, as amostras de água foram coletadas nestas seis nascentes e foz no período de 01 de outubro de 2013 a 30 de setembro de 2014.

Para determinação das propriedades químicas e bacteriológicas: dureza total, amônio, nitrato, nitrogênio, fósforo, coliformes totais e fecais, foram coletadas amostras de água mensalmente, utilizando um recipiente "limpo", com capacidade volumétrica de até $1 / 2$ litro. Foi utilizada a metodologia da água superficial citada em (MAZZER, 2008) e analisadas no laboratório de múltiplo uso. Foi também avaliado trimestralmente a classificação do Índice da Qualidade da Água - IQA - CETESB, que incorpora nove variáveis, $(\mathrm{pH}$, temperatura, oxigênio dissolvido, demanda bioquímica de oxigênio (DBO), turbidez, sólidos totais dissolvidos, nitrogênio total, fósforo e coliformes fecais). Os parâmetros $\mathrm{pH}$ e oxigênio dissolvido foram analisados "in loco" com sonda de multiparâmetros nos dias da coleta.

\section{RESULTADOS}

\subsection{Análises Laboratoriais do Parâmetro Nitrogênio}

O Nitrogênio pode ser encontrado no meio aquático nas seguintes formas: nitrogênio molecular e nitrogênio orgânico. $O$ nitrogênio total apresentou valores acima do estabelecido pelo CONAMA 357 em todos os pontos de coletas (figura 2), possivelmente ao acúmulo de nutrientes derivados da mata. Este resultado condiz com Aun (2007), o qual confirma que a quantificação do nitrogênio orgânico, é constituído principalmente por ureia, aminoácidos e outras substâncias orgânicas com o grupo amino. É importante ressaltar que no ponto 1 - marangoni houveram apenas coletas de sedimentos em todo o período devido a ausência de água na nascente, e que não há limite de detecção de qualidade no solo para os parâmetros apresentados. 


\section{Fórum Ambiental}

da Alta Paulista

Volume 11, Número 06, 2015

Planejamento e Gestão dos Recursos Hídricos

Figura 2: Resultados do parâmetro Nitrogênio em todos os pontos de coleta da Microbacia
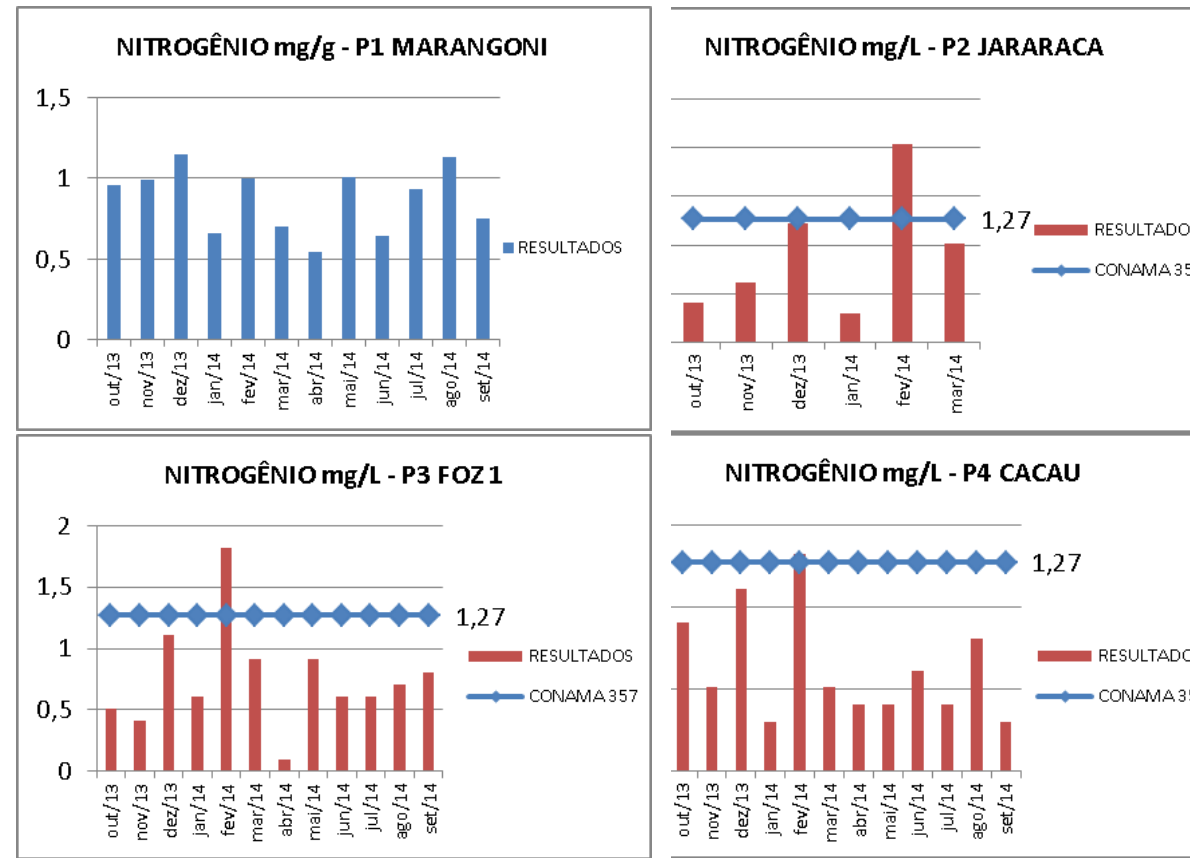

NITROGÊNIO mg/L - P4 CACAU
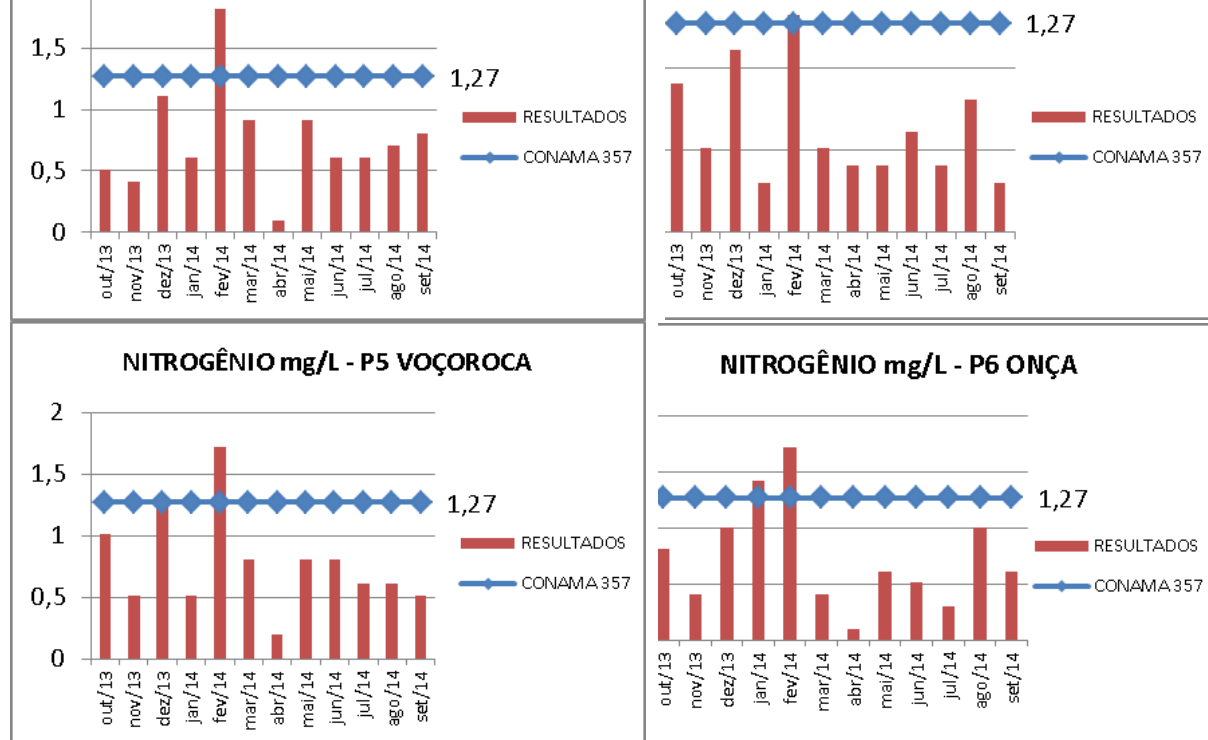

NITROGÊNIO mg/L - P6 ONÇA
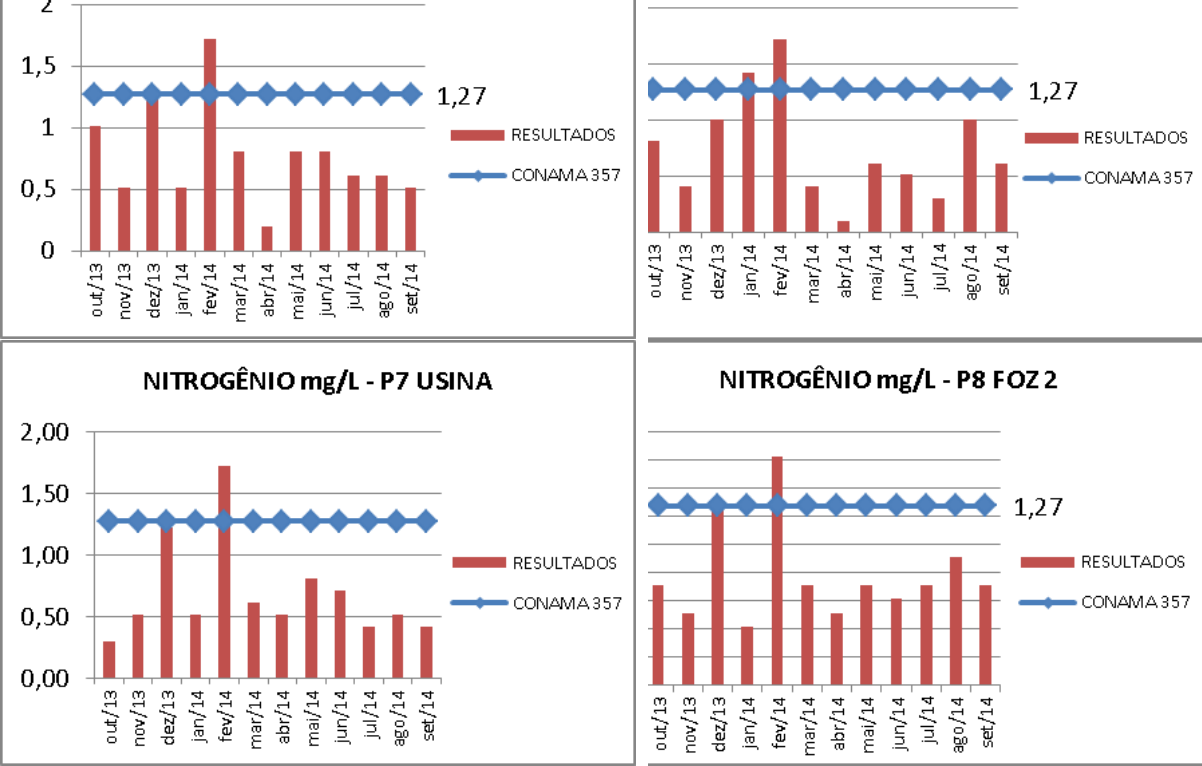

NITROGÊNIO mg/L - P8 FOZ2

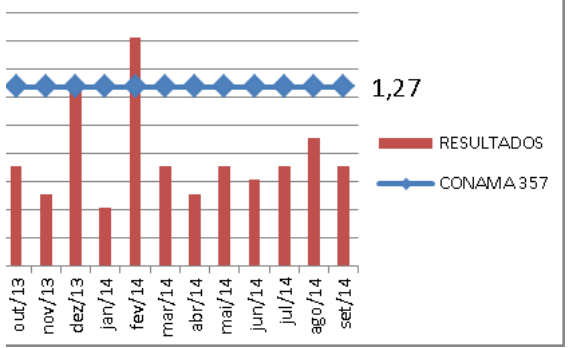

Fonte: RELATÓRIO FAPESP, 2013

\subsubsection{Análises Laboratoriais do Parâmetro Fósforo}

O elemento fósforo na natureza é proveniente da dissolução dos solos e decomposição de matéria orgânica, já a sua ocorrência antrópica pode advir do uso de fertilizantes, despejos domésticos e industriais (SPERLING, 2005). O parâmetro fósforo apresentou valor acima do permitido pelo CONAMA $357 \mathrm{em}$ todos os pontos de coletas, sendo com maior valor nos pontos 2 - foz e ponto 5 - voçoroca, nos 


\section{Fórum Ambiental}

da Alta Paulista

Volume 11, Número 06, 2015

Planejamento e Gestão dos Recursos Hídricos

meses de outubro e fevereiro coincidindo com época de chuva, (figura 3). Considerando que a microbacia é de iminência rural e possui muitas áreas agrícolas, este fato confirma que as atividades antrópicas têm aumentado a concentração do fósforo (WITHERS \& JARVIE, 2008).

Figura 3: Resultados do parâmetro Fósforo em todos os pontos de coleta da Microbacia
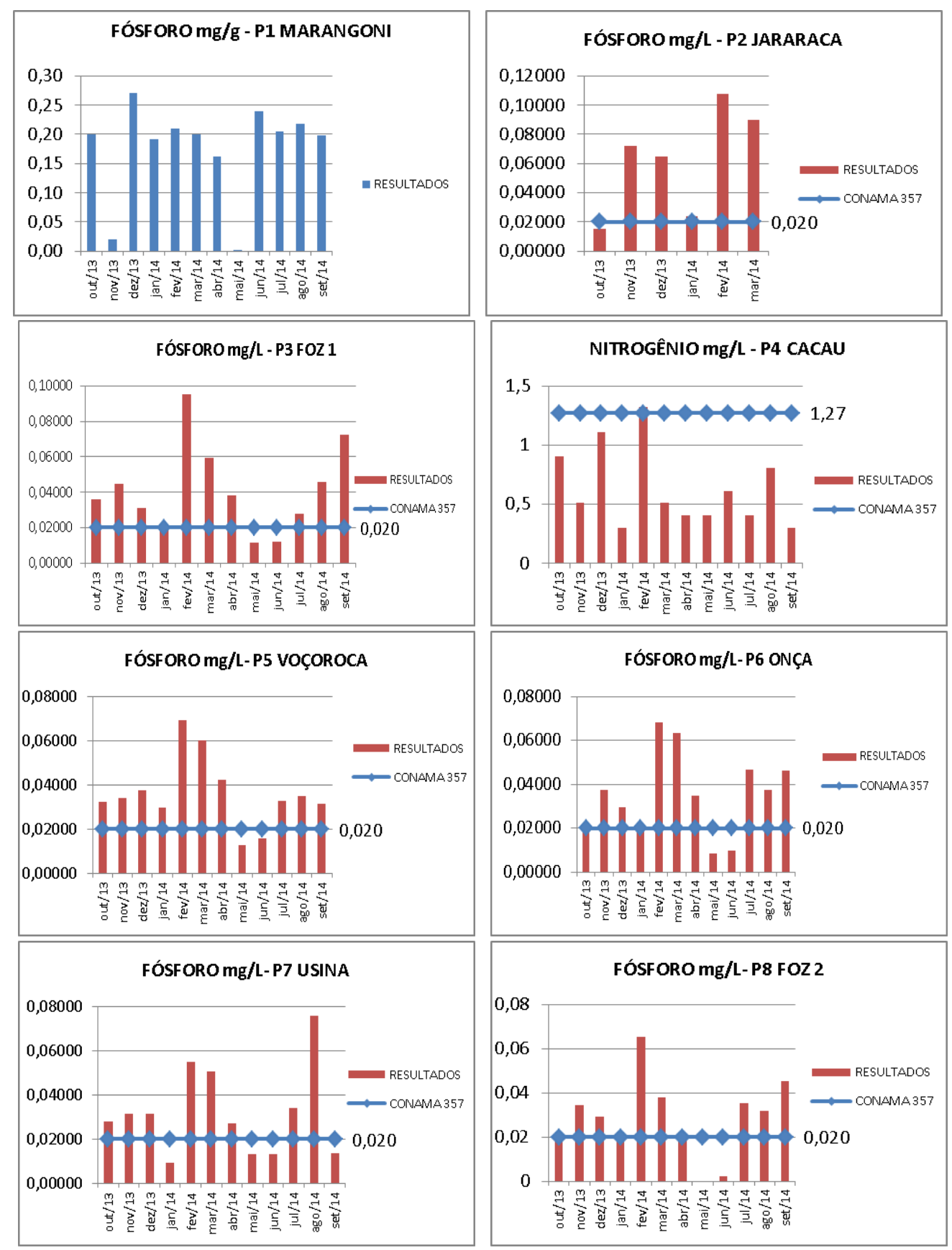

Fonte: RELATÓRIO FAPESP, 2013 


\section{Fórum Ambiental}

da Alta Paulista

Volume 11, Número 06, 2015

\subsubsection{Análises Laboratoriais do parâmetro Dureza}

O maior valor encontrado foi no ponto 6 - onça, com $60 \mathrm{mg} / \mathrm{L}$ (figura 4). Isso ocorreu devido a geologia do local, os processos erosivos incidentes e a própria decomposição da serapilheira. De acordo com Moura et al. (2011), as áreas de pastagem e de constante revolvimento do solo e matas contribuem de forma significativa para o aumento da dureza total nos corpos hídricos

Figura 4: Resultados do parâmetro Dureza em todos os pontos de coleta da Microbacia
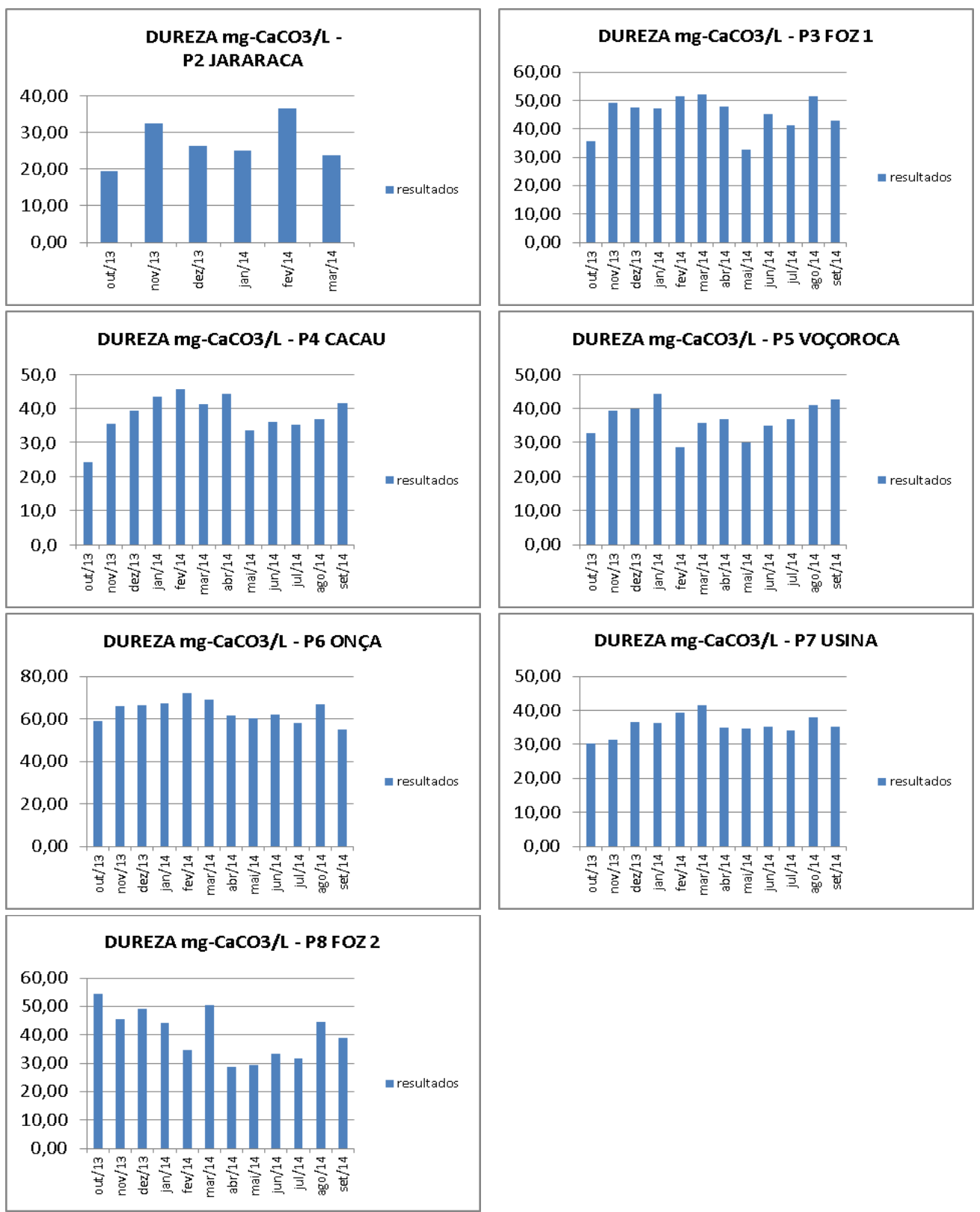

Fonte: RELATÓRIO FAPESP, 2013 


\subsubsection{Análises Laboratoriais do Parâmetro Amônio}

$\mathrm{O}$ amônio pode estar presente naturalmente em águas superficiais ou subterrâneas. $O$ parâmetro foi encontrado em todos os pontos de coleta, com maiores valores no ponto 3 - foz 1 (figura 5). A microbacia contêm 120 ha de mata nativa e possui uma fauna diversificada. $O$ amônio externo relaciona-se com a urina e fezes dos animais, que se aproximam dos corpos de água, e resultam na identificação deste parâmetro.

Figura 5: Resultados do parâmetro Amônio em todos os pontos de coleta da Microbacia

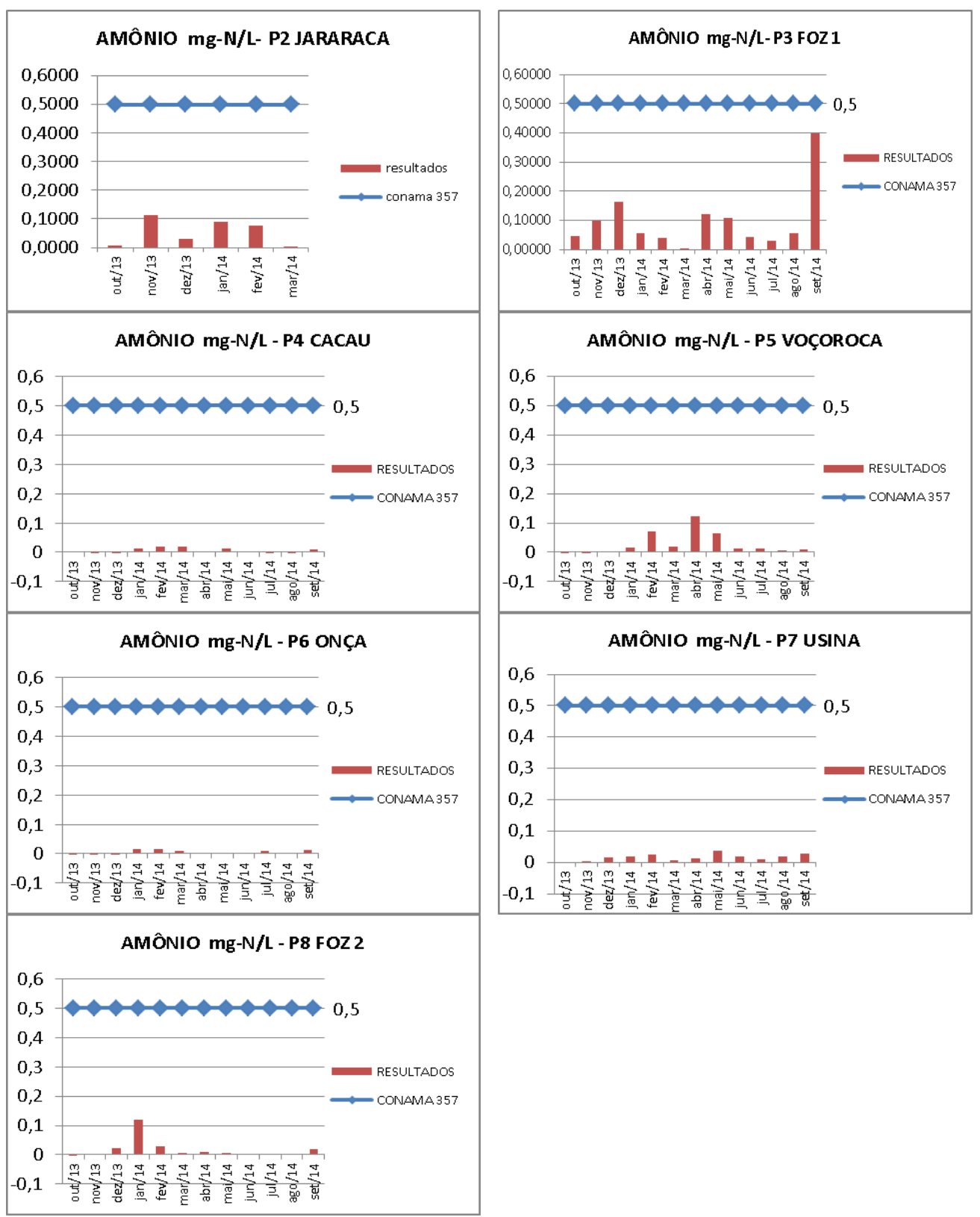

Fonte: RELATÓRIO FAPESP, 2013 


\subsubsection{Análises Laboratoriais do Parâmetro Nitrato}

O parâmetro Nitrato apresentou valor acima do permitido no ponto 4 - cacau (figura 6). Em todo o entorno dessa nascente há práticas agrícolas com cana-deaçúcar, amendoim e milho, que podem gerar resíduos que alcancem os corpos d'água. De acordo com Brito et al. (2005), a concentração de nitrato foi elevada em regiões em que o uso intensivo de fertilizantes e defensivos são em áreas agrícolas.

Figura 6: Resultados do parâmetro Nitrato em todos os pontos de coleta da Microbacia

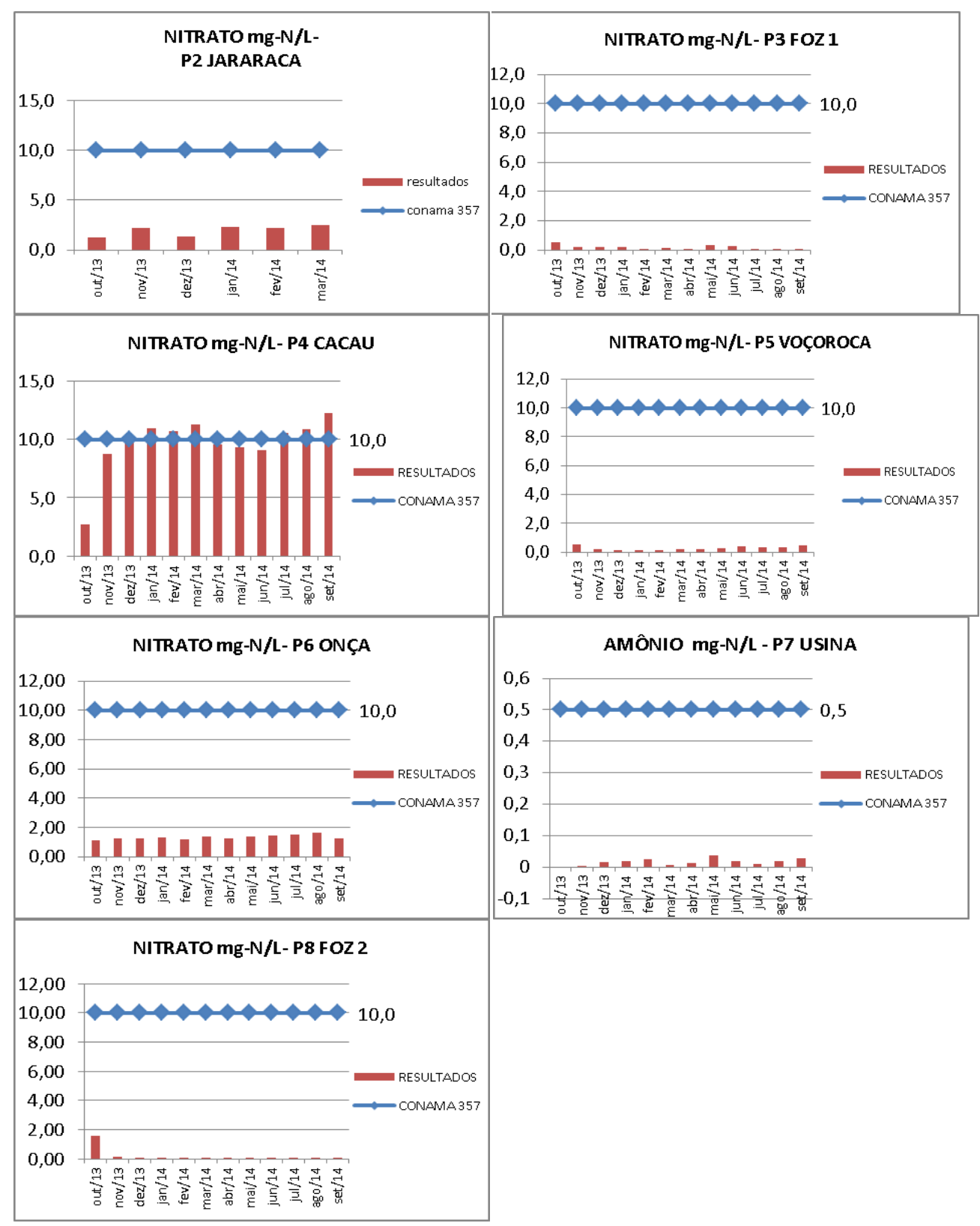

Fonte: RELATÓRIO FAPESP, 2013 


\section{Fórum Ambiental}

da Alta Paulista

Volume 11, Número 06, 2015

\subsubsection{Análises Laboratoriais do Parâmetro Coliformes Fecais}

A contaminação fecal do parâmetro coliforme fecal foi identificada em todos os pontos de coleta (figura 7). Este se origina de fezes de animais de sangue quente da fauna local que entram em contato com a água. Segundo Tortora et al. (2005), a presença da bactéria Escherichia coli na água e alimentos é um indicativo de contaminação fecal, ou seja, por dejetos humanos ou animais de sangue quente.

Figura 7 Resultados do parâmetro Coliformes Fecais em todos os pontos de coleta da Microbacia

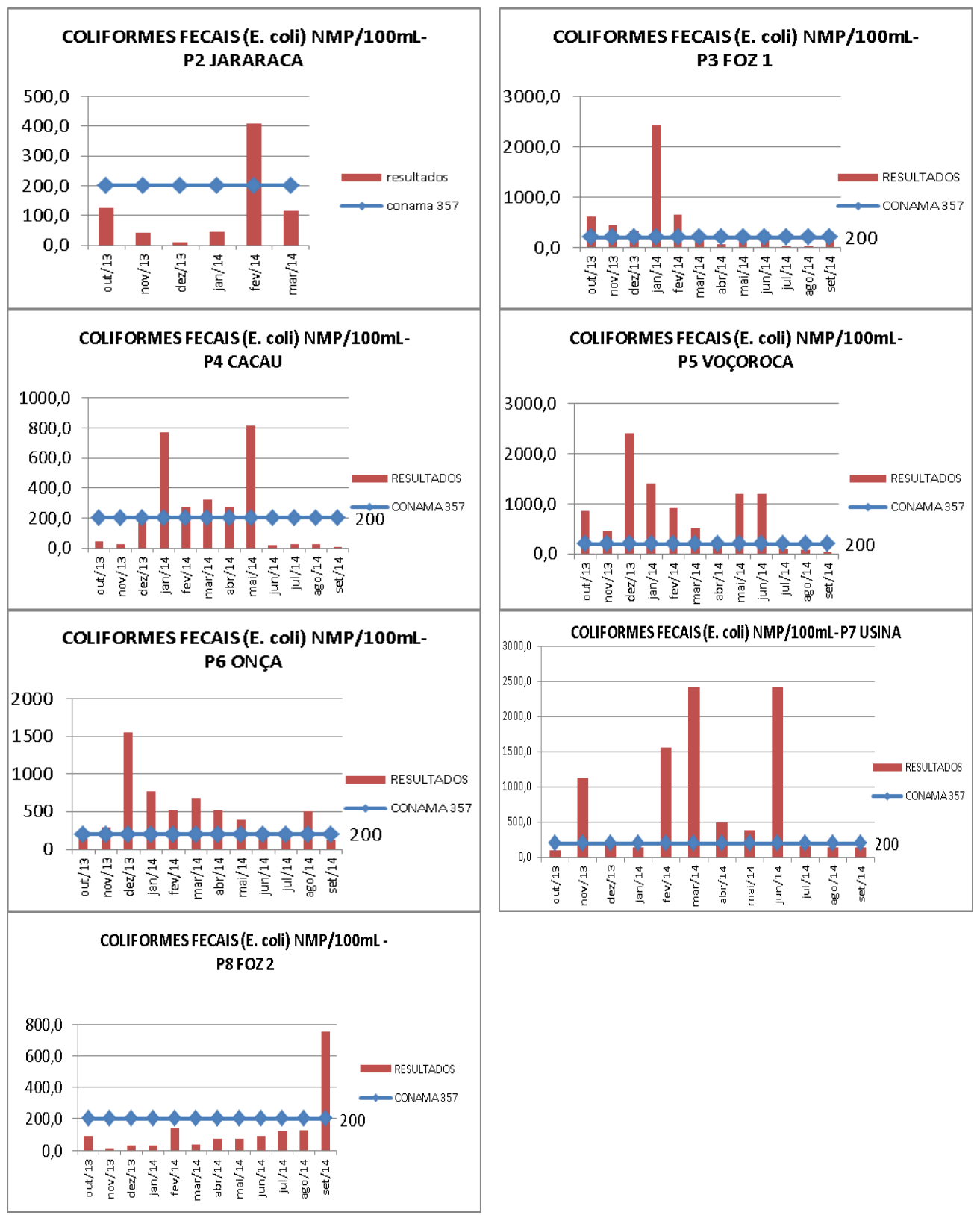

Fonte: RELATÓRIO FAPESP, 2013 


\section{Periódica Eletrânica

\subsubsection{Classificação do Índice de Qualidade das Águas - IQA}

A partir de um estudo realizado em 1970 pela "National Sanitation Foundation" dos Estados Unidos, a CETESB adaptou e desenvolveu o IQA - Índice de Qualidade das Águas que incorpora nove variáveis consideradas relevantes para a avaliação da qualidade das águas, as quais são: Coliformes Fecais, pH, Demanda Bioquímica de Oxigênio, Nitrogênio Total, Fósforo Total, Temperatura, Turbidez, Sólidos Totais Dissolvidos e Oxigênio Dissolvido.

Considerando os resultados dos cálculos do IQA realizado em fevereiro de 2014 e julho de 2014, os pontos de coleta caracterizaram-se por boa qualidade da água. A análise dos resultados permitiu concluir que a qualidade da água da microbacia enquadra-se na classe 2 segundo CONAMA 357/2005, adequada para uso agrícola e biota aquática, conforme tabela 2 abaixo.

Tabela 02: Valores médios dos parâmetros físico-químicos-biológicos, quanto à classificação do Índice da Qualidade da Água (IQA) referente aos limites conforme o CONAMA n. 357/2005 para as classes 2, 3 e 4

\begin{tabular}{|c|c|c|c|c|c|c|c|}
\hline $\begin{array}{c}\text { Fevereiro } \\
\text { 2014 }\end{array}$ & $\begin{array}{c}\text { Ponto 02 } \\
\text { Jararaca }\end{array}$ & $\begin{array}{c}\text { Ponto 03 } \\
\text { Foz 1 }\end{array}$ & $\begin{array}{c}\text { Ponto 04 } \\
\text { Cacau }\end{array}$ & $\begin{array}{c}\text { Ponto 05 } \\
\text { Voçoroca }\end{array}$ & $\begin{array}{c}\text { Ponto 06 } \\
\text { Onça }\end{array}$ & $\begin{array}{c}\text { Ponto 07 } \\
\text { Usina }\end{array}$ & $\begin{array}{c}\text { Ponto 08 } \\
\text { Foz 2 }\end{array}$ \\
\hline $\begin{array}{c}\text { Resultado do } \\
\text { IQA }\end{array}$ & - & 56 & 75 & 70 & 74 & 71 & 57 \\
\hline $\begin{array}{c}\text { Qualidade da } \\
\text { água }\end{array}$ & - & Boa & Boa & Boa & Boa & Boa & Boa \\
\hline $\begin{array}{c}\text { Julho 2014 } \\
\text { Ponto 02 } \\
\text { Jararaca }\end{array}$ & $\begin{array}{c}\text { Ponto 03 } \\
\text { Foz 1 }\end{array}$ & $\begin{array}{c}\text { Ponto 04 } \\
\text { Cacau }\end{array}$ & $\begin{array}{c}\text { Ponto 05 } \\
\text { Voçoroca }\end{array}$ & $\begin{array}{c}\text { Ponto 06 } \\
\text { Onça }\end{array}$ & $\begin{array}{c}\text { Ponto 07 } \\
\text { Usina }\end{array}$ & $\begin{array}{c}\text { Ponto 08 } \\
\text { Foz 2 }\end{array}$ \\
\hline $\begin{array}{c}\text { Resultado do } \\
\text { IQA }\end{array}$ & - & 80 & 69 & 74 & 75 & 73 & 61 \\
\hline $\begin{array}{c}\text { Qualidade da } \\
\text { água }\end{array}$ & - & Ótima & Boa & Boa & Boa & Boa & Boa \\
\hline
\end{tabular}

Fonte: RELATÓRIO FAPESP, 2013

\section{CONCLUSÕES}

Os valores obtidos no monitoramento da microbacia diferiram em cada ponto de acordo com os usos do solo.

A qualidade das águas da Microbacia Córrego da Olaria caracteriza-se por boa qualidade da água segundo a classificação do Índice da Qualidade da Água IQA.

A qualidade das águas do Córrego da Olaria alcança a classe 2 segundo a resolução CONAMA 357/2005. 


\section{Periódica Eletrânica

\section{AGRADECIMENTOS}

A Fundação de Amparo á Pesquisa do Estado de São Paulo (FAPESP) pelo apoio financeiro e institucional.

\section{REFERÊNCIAS}

ANA - Estudo de Consolidação dos Procedimentos Metodológicos na Elaboração do Relatório de Conjuntura de Recursos Hídricos / Relatório final - RF / Estruturação da Base de Dados. Agência Nacional das Águas. Estudos realizados pela empresa TC/BR Tecnologia e Consultoria Brasileira S/A - Brasília, ANA, SPR, 2005118 p.

ALABURDA, J., NISHIHARA, L. Presença de compostos de nitrogênio em águas de poços. Revista Saúde Pública. 1998, vol.32, n.2, p. 160-165.

AUN, M. V. Estudo da remoção de nitrogênio via nitrito e via nitrato em sistemas de lodo ativado alimentados por despejo com alta concentração de fenol. Tese (Doutorado em Engenharia) - Escola Politécnica da Universidade de São Paulo-USP, São Paulo, 2007. 22 p.

BELITZ, K; et al. California Groundwater Quality Monitoring: Framework for a Comprehensive, Statewide Program. Denver Annual Meeting. Geological Society of America. Abstracts with programns, 2004. v. 36, n. 5.

BRASIL. Caderno de recursos hídricos. Agência Nacional das Águas - ANA. Panorama da qualidade das águas superficiais no Brasil. Superintendência de Planejamento de Recursos Hídricos: Brasília, 2005.

BRITO, L. T. de; SRINIVASSAN, V. S.; Silva, A. de S.; GHEYI, H. R.; GALVÃO, C. de O.; Hermes, L. C. Influência das atividades antrópicas na qualidade das águas da Bacia Hidrográfica do Rio Salitre. Revista Brasileira de Engenharia Agrícola e Ambiental, 2005. v.9, p.596-602.

CONAMA - Conselho Nacional do Meio Ambiente (2005). Resolução No 357, de 17 de março de 2005. Ministério do Meio Ambiente. Disponível em: <http://www.mma.gov.br/port/conama/res/res05/res35705.pdf>. Acesso em 08 de maio de 2015.

DONADIO N. M. M., GALBIATTI J. A., PAULA R. C. Qualidade da Água de nascentes com diferentes usos do solo na Bacia Hidrográfica do Córrego Rico, São Paulo, Brasil. Engenharia Agrícola, Jaboticabal, 2005. v.25, n.1, p.115-125.

LEONARDO, H.C.L. Indicadores de qualidade de solo e água para avaliação do uso sustentável da microbacia hidrográfica do rio Passo CUE, região oeste do Estado do Paraná. Dissertação (Mestrado em Recursos Florestais) - Escola Superior de Agricultura "Luis de Queiroz", Universidade de São Paulo, Piracicaba, 2003. 121p.

LOPES, M. C. Ações de Educação Ambiental e Monitoramento da Água no Córrego da Olaria, Apta-Pindorama, SP. Dissertação de Mestrado, Curso de Agronomia, Programa de Pós- Graduação em Ciência do Solo, Universidade Paulista de São Paulo, UNESP - Jaboticabal-SP, 2011. 64 p.

MAGALHÃES Jr., A. P. A situação do monitoramento das águas no Brasil - Instituições e Iniciativas monitoramento das águas no Brasil. RBRH - Revista Brasileira de Recursos Hídricos. Porto Alegre/RS: ABRH, 2000. Vol.5, n³ p. 113-115.

MAZZER, F. R. Caracterização Hídrica em Função das Condições de Uso e Manejo do Solo na Microbacia do Córrego da Fazenda da Glória, Taquaritinga, SP. Dissertação de Mestrado, Curso de Agronomia, Programa de Pós- Graduação em Ciência do Solo, Universidade Paulista de São Paulo, UNESP - Jaboticabal-SP, 2008. 101p. 
Moura, R. da S.; Hernandez, F. B. T.; Leite, M. A.; Franco, R. A. M.; Feitosa, D. G.; Machado, L. F. Qualidade da água para fins de irrigação na Microbacia do Córrego do Cinturão Verde, município de Ilha Solteira. Revista Brasileira de Agricultura Irrigada, 2011. v.5, p.68-74.

REIS, J. S. A. Modelagem Matemática da Qualidade de Água para o Alto Rio das Velhas/MG. Dissertação (Mestrado em Engenharia Ambiental) - Universidade Federal de Ouro Preto. Ouro Preto, 2009. 169 p.

RELATÓRIO TÉCNICO CIENTÍFICO DO PROJETO FAPESP 2013/11932-1. Monitoramento dos Recursos Hídricos para Avaliação das Alterações Associadas ao Uso e Manejo do Solo da Microbacia Hidrografica do Córrego da Olaria. APTA - Polo Regional Centro Norte - Pindorama SP, 2014.

SILVEIRA, A. L. L. Ciclo hidrológico e bacia hidrográfica. In: TUCCI, C. E. M. (Org) Hidrologia: Ciencia e aplicação. São Paulo: EDUSP, 2001. p 35.

SPERLING, M. V. Introdução à qualidade das águas e ao tratamento de esgotos. $3^{\circ}$ ed. Belo Horizonte: UFMG, 2005. 452 p.

TORTORA, G. J. et al. Microbiologia. 8. ed. Porto Alegre, Brasil: Artmed, 2005. 920p.

WITHERS, P. J A; JARVIE, H. P. Delivery and cycling of phosphorus in rivers: A review. Science Of The Total Environment. 2008 p.379 - 395. 